\title{
4919
}

\section{Televisualidade e a realidade dos média}

\section{Ana Velhinho}

\begin{abstract}
Resumo:
A viragem para o século XXI consolida a construção de uma televisualidade, trazida pela naturalização da presença dos meios de comunicação de massas no nosso quotidiano. A fronteira entre o que se pode ver, registar e partilhar no plano público da visualidade é tão ténue quanto controversa, apesar de convocar o cidadão comum para contribuir ativamente para o fluxo de mensagens e imagens que alimentam a rede global e fazem circular uma realidade extra-ecrã, sujeita a um conjunto de filtros e discursos, com acesso e difusão em tempo real. Quando se assiste ao emergir, no seio da ficção, de géneros reality, que operam uma comutação de códigos dirigidos ao consumo e ao espetáculo que caraterizam a hiperrealidade em que vivemos, rapidamente o voyeurismo e a violência passam a integrar os padrões de sociabilidade atuais, pautados pelo imediatismo e superficialidade preconizados pelos média. Estes regimes escópicos produzem no espetador uma relação dual com as imagens, que volatiza o seu papel e autoridade no plano da representação e da vida.
\end{abstract}

Palavras-chave: Cultura Visual; Globalização; Imagens; Média; Televisualidade.

\section{Abstract:}

The shift to the twenty-first century reinforces the ongoing construction of televisuality as a regime associated to the naturalization of mass media presence in our daily lives. The limits to what we can see, record and share on the public ground of visuality get as blurry as controversial in spite of the permanent incitement of common citizens to actively contribute to the flow of images that feed the global network. This circulation sets a type of extra-screen reality processed by filters and discourses translated in real-time access. Simultaneously, the emergence of 'reality' genres within fiction blends all sign codes towards consumption and spectacle that feature the hyperreality in which we live in. Voyeurism and violence rapidly become part of the current patterns of sociability, casted by the immediacy and superficiality of media. These scopic regimes instill in the viewer 
a dual relationship with the images, which volatilizes their role and authority on the domains of representation and life.

Keywords: Visual Culture; Globalization; Images; Media; Televisuality.

\section{Introdução}

O termo "televisual" é descrito por Anne Friedberg e Rainford Guins (2004) como espaço não só associado à televisão e à presença de ecrãs, mas também como um espaço metafísico de visualidade remota, que decorre das alterações que a imagem vista através de um ecrã provoca no espaço, em si, e na sua perceção. O prefixo tele, associado a dispositivos óticos ou de telecomunicação, é entendido como algo que permite ampliar ou aproximar-nos de determinada realidade, o que acentua a importância da técnica (em particular das tecnologias mediáticas do século $X X$ ) para uma nova visualidade - filtrada, traduzida, construída - sendo o ecrã, ou os vários ecrãs que nos rodeiam, o sinónimo supremo desta mediação (Friedberg \& Guins, 2004: 131). Enquanto interface, o ecrã constitui, como refere Lacan, um "anteparo"1 que nos relembra constantemente da construção medial da realidade à qual não conseguimos escapar e que é sobretudo intensificada pela nossa relação quotidiana com os média.

A televisão inaugura, na segunda metade do século $X X$, um novo capítulo da história das imagens e do ecrã, afirmando-se como um "bem doméstico e fenómeno social de massas" que oferece, através de um "lazer massivamente privado", uma experiência de relação muito particular com as imagens, na familiaridade do espaço quotidiano (Lipovetsky \& Serroy, 2010: 203-205). O ambiente de consumo televisivo acaba por marcar os próprios padrões de sociabilidade e cultura do século XXI: um "consumo na distracção", que promove uma indiferença estética inicial que deriva do facto de a televisão dar mais continuidade ao percurso mediático da rádio do que propriamente do cinema (Grilo, 2006: 141). Ao contrário do cinema, a televisão faculta ao homo telespectador apenas um "semi-alheamento", mas que funciona em tempo real e

\footnotetext{
${ }^{1}$ Jacques Lacan (1964) apoia-se nos contributos de Goldstein e Gelb sobre a constituição do campo visual para justificar que o ser humano não consegue percecionar os objetos diretamente: o resultado disto seria como olhar diretamente um feixe de luz, sendo, por isso, necessário um "anteparo", no qual o objeto é recalcado, evitando-se assim o excesso de luz direta. Esta experiência traduz a tese de Lacan de que é necessário projetar o real num plano de mediação - que designa por ecrã ou anteparo - sendo esse ato o momento de fundação do Sujeito ao tomar conhecimento da presença do Outro, já que este plano de mediação resulta da interseção do feixe do olhar do sujeito com a interpelação que o objeto do olhar lhe devolve (gaze). Lacan sublinha, assim, a bidirecionalidade do olhar, onde o Outro nos fita de volta. Também W.J.T Mitchell (2005) tem uma postura semelhante, ao alertar para o fato de que também as imagens olham de volta o espetador e o desejo delas é ser olhadas.
} 
planetariamente - a "aldeia global" proposta por McLuhan (Lipovetsky \& Serroy, 2010: 203-205), é hoje exponencialmente amplificada pelo advento da Internet e o boom da partilha de conteúdos online pelo cidadão e utilizador comum, potenciadora de uma visualidade globalizada.

\section{Magnetismo televisivo}

A popularização da televisão na cultura de massas, sobretudo ao nível do entretenimento, verificou-se também noutros domínios, nomeadamente no contexto educativo, pela sua eficácia comparativamente com a apreensão de informação registada através de outros meios de comunicação como a rádio ou a imprensa. Referindo-se à televisão como um "meio frio", em oposição aos "média quentes"como a imprensa ou o cinema ${ }^{2}$, McLuhan ressalta na TV a unificação sensorial que esta solicita, traduzindo-se numa experiência de profunda envolvência:

A imagem televisiva requer que a cada instante "fechemos" os espaços da trama através de uma participação sensual convulsiva que é profundamente cinética e tátil, porque o tacto é a interação dos sentidos, ao invés do contacto isolado da pele e do objeto. (McLuhan, 2003: 342). ${ }^{3}$

A televisão revela-se, assim, como um meio sedutor que apela à audiência, através de um fluxo de imagens que oferecem uma qualidade historicamente pobre e de fraca definição, mas cujo modo de apresentação - uma irradiação de luz num mosaico fragmentado - prende o espectador ao ecrã, levando mesmo o autor a afirmar que, com a TV, o espectador é o ecrã (McLuhan, 2003: 342). É nesse sentido que consolida, mais uma vez, a sua máxima segundo a qual "o meio é a mensagem", na medida em que é esta dimensão sinestésica da experiência televisiva que produz um efeito poderoso nos espectadores, independentemente dos conteúdos emitidos.

Marshall McLuhan encara a televisão como uma das extensões mais poderosas do sistema nervoso central, afirmando-a como um meio de reação mais do que de ação. $O$ polémico teórico dos média carateriza a imagem televisiva como uma gestalt pulsante ${ }^{4}$ catalisadora de uma sinestesia global que toma conta do sistema percetivo e instala um

\footnotetext{
2 McLuhan (1977) carateriza os "meios quentes" como aqueles pertencentes à Galáxia Gutenberg (tais como a imprensa, a rádio, o cinema), centrados em sentidos específicos, com um tipo de representação de alto detalhe e definição, de apresentação sequencial e especializada que requer do observador uma atenção analítica e exige pouca participação. Por oposição, os "meios frios" utilizam vários estímulos sensoriais para transmitir uma imagem com menor definição, mais fragmentada e dispersa, na medida em que está associada à simultaneidade e à múltipla perspetiva, exigindo do espectador uma maior participação em termos de envolvimento (uma participação fisiológica e não propriamente intelectual) para completar a informação em falta. Esta tipologia de meios está mais relacionada com a revolução eletrónica, podendo ser aplicada à televisão, ao vídeo e ao computador.

${ }^{3}$ Tradução da autora.

4 "[...] é mais fiável 'apresentar' a TV como uma gestalt complexa de dados recolhidos quase ao acaso." (McLuhan, 2003:346); tradução da autora.
} 
regime de "narcose" ${ }^{5}$, por muitos entendido como alienador, mas por outros encarado como um ativador sensorial fascinante. A superficialidade e imediatismo ${ }^{6}$ deste tipo de imagem são frequentemente apontados pelos críticos como dissuasores da memória, que a esvaziam não só de sentido mas também da afetividade que inevitavelmente colocamos nas imagens com as quais nos relacionamos. Conforme afirma Adriano Duarte Rodrigues, referindo-se ao dispositivo televisivo:

A neutralização desta relação dromoscópica é um dos efeitos do dispositivo, um dos efeitos mais extraordinários da sua acção performativa. Este efeito está intimamente associado à acção viral das imagens, à sua natureza febril e contagiante ou, se preferirmos, à acção de entorpecimento provocada pela natureza totalizante do mundo que deixa ver (Rodrigues, 1989: 63).

Em oposição a tais críticas dominantes nos estudos televisivos, maioritariamente centrados em aspetos psicanalíticos subjacentes às teorias do dispositivo, John Thornton Caldwell apresenta no livro Televisuality: Style, Crisis, and the Authority in American Television (1995) uma perspetiva diferente sobre a TV. O autor aborda a plasticidade da imagem televisiva, a partir do seu conhecimento académico e prático da indústria enquanto produtor de vídeo e, com base no legado da obra Visible Fictions (1982) de John Ellis, refere-se a uma visualidade objetificada ("videographic artobjects"), que alimenta o desejo pela superfície das imagens, ostentado pelas massas: "A nova televisão não depende nem do efeito de realidade nem do efeito de ficção, mas do efeito de imagem" (Caldwell, 1995: 152) ${ }^{7}$. Caldwell apresenta, assim, uma definição de "televisualidade" como fenómeno decorrente dos meios de comunicação de massas, no período pós-modernista de finais dos anos 80 , com especificidades técnicas e programáticas, mas sobretudo centrado sobre a audiência - a cultura popular de massas. Digno de destaque é o chamado estilo MTV, enquanto género "pósdependente" (Dancyger, 2011), ou seja, dependente de artifícios de pós-produção que Ihe conferem uma sofisticação que atinge a sua época áurea no início dos anos 90 e define um marco histórico na estética quer dos videoclips quer da própria retórica televisiva. Trata-se de um estilo que importa muitos princípios fílmicos dos spots publicitários, em justaposição a referências diretas a outros formatos e média, numa linguagem visualmente estimulante, liberta do espaço-tempo narrativo do cinema que

\footnotetext{
${ }^{5}$ Termo utilizado em alusão ao estado simultâneo de alucinação e entorpecimento causado pelas extensões tecnológicas que, ao convocar uma "simbiose hipnótica" de todas as faculdades, transformam a vivência perceptiva em alucinação. Neste sentido, McLuhan traça uma relação direta entre o conceito de "narcose" e o conceito de "narké", do qual deriva etimologicamente o nome de Narciso, que, segundo o mito grego de Ovídeo, sucumbe fascinado pela extensão de si mesmo, o seu simulacro (Castello Branco, 2013:284289).

6 “Nas imagens televisivas, as coisas são-nos dadas totalmente de uma só vez; não há nelas nada mais do que aquilo que elas nos dão a ver. Daí o seu fascínio, esta espécie de completude originária, oferecendonos do mundo uma percepção totalizante, sem esforço" (Rodrigues, 1989:63).

${ }^{7}$ Tradução da autora.
} 
tem como referente a realidade. O desprendimento da narrativa dá lugar a um investimento na experiência emocional condensada no tempo, construída com recurso a estratégias de edição que rompem com a continuidade da mensagem e apostam no ritmo e diversidade visual em resposta à sede de irreverência e inovação de um público jovem e rebelde ${ }^{8}$.

Na sua abordagem essencialmente formalista, Caldwell defende a televisão como um meio de comunicação promissor e contraria de forma veemente a teoria dominante dos média, que considera estar totalmente apartada da indústria de produção e exclusivamente centrada na crítica ao poder ideológico e hipnotizante da TV. Em oposição à ideia do observador clássico, sodomizado pelo magnetismo de ver televisão, considerado como um efeito inerente à própria condição de espectador do dispositivo televisivo (veja-se a este propósito o conceito de "fluxo") ${ }^{9}$, Caldwell chama a atenção para as potencialidades de novas formas de liberdade asseguradas pelo desenvolvimento das tecnologias do vídeo e da televisão por satélite, que viriam a atribuir um papel mais ativo ao telespectador. A este nível, além da utilização do telecomando, somam-se as alternativas introduzidas pelos canais por cabo, que apostam em programação temática que se adapta estilisticamente à diversidade de públicos e disponibiliza conteúdos e funcionalidades interativas, em permanente reinvenção de acordo com as necessidades e sugestões introduzidas pela audiência, reveladoras da sua importância crescente.

A condição do telespetador enquanto figura central no processo comunicativo dos média tem vindo a suscitar diversos tipos de reflexão, não só por parte de teóricos mas também de artistas. As obras TV Buddha (1974) de Nam June Paik e Facing a Family (1971) de Valie Export constituem-se como formas de materializar e mostrar aos espectadores a incontornável presença e influência conquistada pela televisão, enquanto meio de consumo solitário ou coletivo, sendo a noção de feedback fundamental para compreender a emissão televisiva como um circuito do qual a audiência é parte integrante. Facing a Family foi projetada como peça de TV action, tendo sido emitida

\footnotetext{
8 "Claramente, um filme que se concentra em estados de espírito vai apelar apenas a um público familiarizado - um público jovem que assiste e disfruta da visualização consecutiva de videoclipes, que não apresentam qualquer ligação narrativa mas fornecem individualmente uma sensação ou sentimento distinto. Este público não se importa com a fragmentação, ritmo ou brevidade da experiência. Para este público, o estado de espírito é uma experiência audiovisual desejável" (Dancyger, 2011: 168); tradução da autora.

${ }^{9}$ Conceito proposto por Raymond Williams na sua obra Television: Technology and Cultural Form (1974) resultante da mediação entre a tecnologia e o conteúdo televisivos, num fluxo pré-programado assente em estratégias intertextuais de forma a maximizar a audiência. Para Frederic Jameson (2003) o conceito de "fluxo" ou "fluxo total" corresponde igualmente à noção de "fluxo de signos" enquanto algo que resiste a qualquer estrutura ou sentido, ideia que associa essencialmente ao vídeo e à noção de texto pósmoderno, onde se verifica uma sobrevalorização da experiência em si em detrimento do conteúdo visualizado.
} 
em direto, imiscuída subversivamente no sistema televisivo nacional, como parte do programa Kontakte do canal austríaco ORF (Mueller, 1994), no qual, durante cinco minutos, as famílias em suas casas puderam visualizar uma família a assistir televisão enquanto jantava, devolvendo-lhes, como num espelho em mise en abyme, a imagem da sua condição de espectadores incorporados no sistema e nos seus códigos.

O magnetismo psíquico apontado pela teoria do "fluxo total" encontra-se subliminarmente presente em obras de Nam June Paik: não só em TV Buddha (1974) numa alusão metafórica, mas sobretudo na abordagem literal de uma das suas obras seminais, Magnet TV (1965). Esta peça tira partido da tecnologia eletromagnética da televisão para a exploração formal da imagem, cuja distorção resulta de interrupções do sinal, como produto da interação direta de um íman sobre o televisor. Nesta obra, o artista chama a atenção para o magnetismo não como forma de domínio ideológico sobre a audiência, mas como instrumento expressivo para a criação plástica de uma estética disruptiva e ilegível. A sua abordagem simultaneamente tecnológica, visual e escultórica, mas essencialmente ontológica sobre o dispositivo, posiciona-o como figura central no panorama da media art, tal como afirma John Handhart, curador de uma das maiores retrospetivas do artista no Museu Guggenheim no ano 2000:

Vou argumentar que Paik percebeu a ambição do imaginário cinematográfico patente nos filmes independentes e vanguardistas ao tratar o filme e o vídeo como formas de arte 'multitextuais' flexíveis e dinâmicas. Ao usar a televisão, bem como as modalidades da gravação de vídeo monocanal e formatos escultóricos e de instalação, ele imbuiu de novos significados a imagem electrónica em movimento. As investigações de Paik sobre o vídeo e a televisão e o seu papel decisivo na transformação da imagem electrónica em movimento num medium artístico fazem parte da história das artes dos média (Handhart, 2000). ${ }^{10}$

Nam June Paik viu na televisão um meio de expressão capaz de ultrapassar barreiras planetárias, num período em que a ideia vaga do que seria a Internet era apenas ficção científica, tal como o era a visão totalitária do mundo em Mil Novecentos e Oitenta e Quatro projetado por George Orwell. Como referência direta à famosa obra do escritor, Paik emitiu exatamente nesse ano um programa de TV que designou por Good Morning, Mr. Orwell, com o intuito de desmistificar a visão denegrida e estereotipada do meio televisivo, entendido como ameaçador, mas sobretudo como disseminador de conteúdos homogeneizados de baixa qualidade. Nesta ótica, os conteúdos da TV são vistos como um fast-food pré-digerido para as massas, que veicula mensagens simplificadas e espetacularizadas ${ }^{11}$, fascinantes pela promoção de uma adesão

\footnotetext{
${ }^{10}$ Tradução da autora.

${ }^{11}$ Na sua obra A Sociedade do Espetáculo (1967) Guy Debord lança as bases da teoria do espetáculo, através da crítica a uma sociedade capitalista, instrumentalizada pela técnica e pelos meios de comunicação de massas que promovem um discurso hegemónico, resultando numa alienação do espectador que se relaciona com o mundo através de imagens, constituindo uma "realidade pseudónimo"
} 
emocional que não exige qualquer esforço intelectual. A previsibilidade e banalidade do que é visto tornam-se tranquilizantes para o espectador, apresentando-lhe um mundo que conhece e do qual se sente participante, no conforto do seu lar.

Nam June Paik posiciona-se, porém, num espectro diametralmente oposto, e aproveitou precisamente a obra Good Morning, Mr. Orwell para nos apresentar o potencial de partilha cultural, que combina conteúdos eruditos (high brow) e de entretenimento (low brow), como forma de provar que a televisão é capaz de apelar a um público de diferentes estratos e refletir o mix programático como abordagem semelhante ao próprio zapping, que se tornara uma prática comum inerente ao ato de assistir televisão. A emissão em direto a partir de dois pontos distintos - a WNET TV de Nova lorque e o Centro Georges Pompidou em Paris - colocou no ar performances ao vivo de diversos artistas convidados, intercaladas com gravações de trabalhos de videoarte e grafismo televisivo criados por Paik. O programa destacou-se pela diversidade de códigos visuais, desde a apresentação com um pivot, até estratégias de divisão do ecrã em múltiplas janelas, simultâneas ou sobrepostas, para evidenciar o diálogo entre localizações distintas, ou mesmo a emissão multicâmara, como aconteceu na performance de Joseph Beuys e sua filha em Paris, remixada por Nam June Paik. Simultaneamente decorria em Nova lorque uma atuação de John Cage, emitida de forma alternada com a atuação de Beuys e outros artistas, reforçando a ideia de um acontecimento intercontinental ao vivo, embora remoto.

\section{Da televisualidade global aos géneros reality}

Apesar do entusiasmo de muitos artistas ligados à media art, os preconceitos dos eruditos, bem como os receios instalados pelo estigma de regimes ditatoriais promotores de uma visão orwelliana do mundo, teceram reservas a um entendimento demasiado otimista sobre as tecnologias de informação e comunicação, que desenham, na década de 80 , uma trajetória definitiva para uma comunicação sem fronteiras, que viria em poucos anos a reconfigurar, gradualmente, os restantes meios de comunicação. Os anos 90 são marcados pelo uso pleno do computador pessoal e a exploração comercial da rede global - a Internet - através do seu sistema de informação hipertextual, a World Wide Web. Depois do aparecimento do primeiro bowser em 1991, assiste-se em 1994 à criação de centenas de milhares de websites online, que na viragem do milénio se traduzem em milhares de pessoas a gerar tráfego para biliões de páginas.

afastada numa representação cuja finalidade é a mera contemplação (Debord, 1991:9). Segundo o autor, "o espetáculo não é um conjunto de imagens, mas uma relação social entre pessoas, mediatizada por imagens." (Debord, 1991:10). 
Neste intervalo temporal, um jovem programador que se afirma como artista conceptual antecipa de forma visionária, embora completamente inortodoxa, um conjunto de premissas que estariam na base, segundo o próprio, de uma "Terceira Guerra Mundial" anunciada pelas novas tendências da tecnologia. Responsável pelo conceito de "Festa Interativa" que reúne fisicamente comunidades de nerds rodeados por mulheres, álcool e videojogos como verdadeiras ciberestrelas, e pela fundação da primeira produtora de televisão por internet, a Pseudo.com, Josh Harris afirma-se como percursor na exploração de uma nova forma de sociabilidade, mediada pela tecnologia, tirando partido da emissão vídeo e chat em tempo real, disponibilizada através de uma interface gráfica online. A polémica Pseudo.com chegou mesmo a ser comparada pelo jornal New York Times à Fabrica de Andy Warhol (sendo Josh Harris descrito como o "Warhol da TV Web").

Josh Harris, apresentado pela realizadora Ondi Timoner ${ }^{12}$ como "o pioneiro da Internet de que ninguém ouviu falar", assume-se como produto de uma geração criada em frente da televisão, cuja educação e referente familiar tiveram maior ligação com personagens de ficção do que com seres humanos. Este facto teve repercussões no seu percurso pessoal e profissional, em obras como Lauder my head (1992), onde apresenta uma animação gráfica que exibe repetidamente o trocadilho irónico "Come form with me", a par de megaproduções como Quiet (1999) e We Live in Public (2000) que consolidam o seu ponto de vista sobre o futuro da tecnologia:

A Internet é como uma nova experiência humana. No início toda a gente vai gostar. Mas haverá uma mudança fundamental na condição humana. O tempo passa e transformas-te nestas caixas virtuais cada vez mais restritas. Cada ação nossa será contabilizada. Um dia, todos nós iremos acordar e perceber que somos apenas servos $^{13}$ (Harris apud Timoner, 2009). ${ }^{14}$

Harris transporta literalmente esta visão de caixas virtuais para o projeto Quiet: We Live in Public (1999), a sua versão high-tech do Big Brother ${ }^{15}$, estabelecido como uma

\footnotetext{
12 Josh Harris é protagonista do documentário biográfico We Live in Public (2009), realizado por Ondi Timoner ao longo de dez anos a partir de 5000 horas de gravações, galardoado com o Grande Prémio do Júri no Festival Sundance de Cinema.

${ }^{13}$ Análoga metáfora de subserviência foi utilizada por Vilém Flusser (1985), para descrever o modo como a fotografia transforma o homem em seu "funcionário", enquanto paradigma de inscrição da técnica no mundo moderno traduzido numa robotização da vida.

${ }^{14}$ Tradução da autora.

${ }^{15}$ Designação icónica associada à ideia de regulação contínua e totalizante, como mecanismo que exerce poder de forma ubíqua, cunhada em 1949 por George Orwell, ano em que foi publicada a sua obra Mil Novecentos e Oitenta e Quatro. O romance de ficção científica assenta na premissa do "grande irmão" como um ser omnipresente e omnisciente que olha por nós ("Big Brother is watching you"), afirmando-se como uma das figuras de ficção mais emblemáticas de todos os tempos, alvo de apropriações de vários tipos, nomeadamente sob a forma de adaptações para cinema (em 1956 por Michael Anderson e em 1984 por Michael Radford), e ainda da apropriação da expressão "Big Brother" para o título de um programa televisivo de entretenimento em 1999, posteriormente adaptado para vários países, enquanto expoente máximo do género reality $T V$.
} 
comunidade de cem voluntários instalados num "hotel cápsula", construído numa cave de um prédio em Nova lorque. Os participantes eram acompanhados por uma equipa técnica e filmados 24 horas por dia durante um mês, sendo que cada casulo individual (pod) e as áreas comuns eram aparelhados com câmaras, microfones ultrassensíveis e monitores. Era possível sintonizar qualquer canal a qualquer momento e, se dois terminais estivessem sintonizados no mesmo canal, podiam dialogar. O projeto foi caraterizado pelos produtores como um misto entre um evento, uma festa e uma experiência social, com base na estruturação de uma sociedade livre, anárquica e disfuncional, com acesso gratuito a comida, álcool, drogas e armas, disponibilizando igualmente uma igreja e acompanhamento psicológico.

No processo de recrutamento para cidadãos de Quiet, os candidatos tinham de usar uniforme e ser sujeitos a interrogatórios, individuais e de grupo, testes de personalidade e questionários, onde tinham de abdicar da sua privacidade, além dos seus direitos de imagem. Cada membro da equipa técnica era designado por artista, havendo desde o artista de interrogatório, que abordava questões políticas, religiosas e sexuais, até ao artista de vigilância, responsável pela monitorização das imagens capturadas. Todo este contexto, aparentemente fascista, era aceite pelos participantes de forma consensual, pois, tal como verificado pelos técnicos, a partir do momento em que alguma ação é solicitada perante a lente de uma câmara, a atenção deixa de recair sobre o teor dessa ordem para passar a centrar-se sobre o poder que a visualização dessas imagens confere ao sujeito vídeo-gravado, transformando-o numa celebridade.

Passado algum tempo, o efeito da vigilância absoluta, aliado a comportamentos de excesso, começou a traduzir-se nos participantes num sentimento de dissociação de si próprios, desligados de emoções e empatia, como ratos de laboratório. A adrenalina e entusiasmo iniciais transformaram-se em agressividade e depressão, muitas vezes já latentes nos participantes, outras vezes desencadeadas por esta experiência-limite desmantelada a 1 de janeiro de 2000 por intervenção da polícia, que julgou estar face a uma tentativa de suicídio em massa por parte de um culto do juízo final. Para Harris, este projeto, a par de todos os outros em que se envolveu, acabou por se traduzir numa falência financeira e emocional, que, não obstante, foi bastante reveladora. Com efeito, embora parecesse estranha e futurista na altura, esta experiência mostrou-se incrivelmente próxima da realidade contemporânea, onde se assiste ao aparecimento crescente de programas de caráter voyeurista emitidos pelos média, com enorme poder de mobilização da audiência. Como o próprio Josh Harris afirma, "O Big Brother não é 
uma pessoa. É a consciência coletiva que observa" (esta definição é-nos dada por Harris no documentário de Timoner, estreado em 2009). ${ }^{16}$

No outono de 2000, Harris deu início a uma nova obra com um conceito semelhante, mas agora disseminada pela Internet - We Live in Public -, para a qual instalou câmaras e microfones permanentemente ligados na casa que partilhava com a sua namorada. No website disponibilizava uma interface com output de vídeo e um chat através do qual interagiam com os espectadores em tempo real. As pessoas seguiam-nos online e interferiam na sua relação, dando conselhos ou fazendo solicitações, chegando mesmo a comprar cassetes de vídeo com gravações de momentos específicos - literalmente compravam partes da vida deste casal. Do romantismo da partilha de afetos entre um casal comum, ao voyeurismo das cenas íntimas de sexo ou higiene pessoal, tudo era escrutinado sem filtros, algo que Josh Harris comparava a um mind sharing.

Mais uma vez, o enorme sucesso inicial deu lugar a mudanças comportamentais e de dinâmica entre o casal. Ambos começaram a afastar-se e a deixar de falar e interagir, estando mesmo mais próximos dos espectadores online do que entre si. Na sequência de uma discussão, o casal alcançou um ponto de não retorno e Tanya abandonou Josh, com o argumento de que todo o aparato do programa havia consumido a relação. Curiosamente, mais do que aferir o estado um do outro após a discussão, ambos tiveram a preocupação principal de tentar saber a reação dos utilizadores do chat. Após a saída de Tanya, verificou-se uma redução de quase $90 \%$ das visualizações e, já num estado de falência financeira, Josh admitiu estar mentalmente doente e desapareceu do plano de celebridade em que havia vivido nos últimos anos. Mais tarde, viria a afirmar Tanya como uma namorada falsa, referindo-se a ela como uma "namorada Truman Show". Ao contrário de Quiet, em que Harris tinha o controlo, em We Live in Public ele passou a ser o rato de laboratório da sua própria experiência dentro do ecrã e, desta vez, sem o telecomando. Atualmente, Josh detém os direitos de imagem de milhares de horas de gravações nas quais é possível testemunhar reações e opiniões, na primeira pessoa, daqueles que experienciaram na vida real ${ }^{17}$, ainda sem interesses instalados de exploração comercial, um dos atuais negócios mediáticos mais rentáveis, comummente designado por reality TV.

A telerrealidade explora o potencial dramático do banal, tendo como principal consequência a criação de celebridades instantâneas e fugazes que atingem picos de audiência superiores à média e despoletam práticas de consumo preconizadas pelos

\footnotetext{
${ }^{16}$ Tradução da autora.

17 Entre os participantes de Quiet encontravam-se não só pessoas anónimas mas também artistas emergentes ligados à ciberarte e à performance. Destaca-se a participação da vanguardista Alanna Heiss, diretora do MoMa PS1 entre 1976 e 2008, que caraterizou esta experiência como uma oportunidade única, embora hardcore e utópica.
} 
intervenientes, que se transformam em modelos a seguir, com os quais facilmente nos identificamos. Dependendo do enfoque, os reality shows podem ser categorizados em vários subgéneros que, de forma abrangente, vão dos concursos de talentos e de lifestyle às chamadas novelas da vida real (docusoaps), com famosos ou pessoas anónimas. Além do potencial mercantil deste tipo de programação, disseminado através de uma convergência multiplataforma ${ }^{18}$, a regularidade da sua emissão cria uma fidelização de espectadores, que passam a seguir de forma ritualizada cada episódio, tornando esta realidade mais interessante do que a sua própria vida, que é literalmente deixada em stand-by.

Das câmaras ocultas de programas de humor como Candid Camera (1948), considerado o precursor da televisão realidade, à promiscuidade e humilhação emocional a que hoje se assiste em família em pleno horário nobre, foi apenas um pequeno passo. A realidade tal como ela é, alegadamente sem guião, rapidamente deu lugar a uma receita de sucesso, tecnicamente construída pela indústria dos média para criar o artifício necessário à sua impressão de realidade. A edição cuidada de planos (que importa do cinema toda a intensidade dramática), ou imagens em bruto sem edição (a que podemos aceder 24 horas por dia mesmo quando não se passa absolutamente nada), dão ao espectador a sensação de omnividência e controlo total sobre cada acontecimento.

The Truman Show (1998) representa o epítome deste conceito da vida em direto levado ao extremo, numa tragicomédia pós-orwelliana que assenta no poder de manipulação dos média, um ano antes de experiências como We Live in Public ou como a primeira edição do programa televisivo Big Brother. Todo o filme é uma sátira ao mundo perfeito que aparece no pequeno ecrã, tão perfeito que Seahaven nos aparece como uma cidade-estúdio gigante, cujos limites são ditados pela hidrofobia induzida no protagonista Truman Burbank, que o impede de atravessar a ponte que o separa do desconhecido. O seu quotidiano banal, feito de rotinas, rapidamente dá lugar a uma teoria da conspiração que Ihe sugere que todo aquele mundo de perfeição asséptica gira à sua volta e o vigia a cada gesto. Todo o presente é fabricado pelas notícias que Ihe chegam pela rádio ou televisão, todo o seu passado foi construído em álbuns de

\footnotetext{
${ }^{18}$ A convergência multiplataforma refere-se a uma estratégia integrada de comunicação mediática que tira partido da possibilidade de acesso a conteúdos através de vários meios e suportes que funcionam em articulação e complementaridade, incentivando o consumo de conteúdos multimédia nos vários canais. Este tipo de abordagem tem-se generalizado como paradigma de comunicação contemporâneo aplicável a qualquer entidade - fenómeno que Henry Jenkins chama de Convergence Culture (2008) -, particularmente explorado na área dos média e do entretenimento. Os grandes grupos económicos ligados à comunicação social são um dos principais sectores que procura tirar partido da especificidade de cada canal de comunicação, preconizando uma informação acessível e atualizada a qualquer hora, em qualquer lugar e através de qualquer dispositivo.
} 
memórias sem referente. Desde o dia em que nasceu, como propriedade de uma produtora televisiva e como criação de um "tele-visionário", toda a sua vida foi dirigida como uma peça de ficção, num micromundo que é o próprio interior da caixa mágica, o plano de imagem do qual finalmente consegue sair ao atravessar a porta do cenário, que é a saída do quadro-janela, a moldura albertiana que separa o público do privado e separa a imagem da realidade.

O romper da alienação implicou uma mudança rumo ao desconhecido - a receita hollywoodesca da clássica viagem do herói que parte à descoberta. O catalisador desta mudança é uma mulher e a tentação de experimentar o proibido, sendo o amor a força motriz que escapa ao controlo subliminar que, a cada instante, tenta inibir o protagonista da sua capacidade de livre arbítrio. O domínio privado da nossa subjetividade e da liberdade de pensamento crítico, instigado pelas emoções e pela necessidade de expressão e comunicação, é uma ameaça ao poder de modelação que sistemas totalitários - políticos e mediáticos - conseguem aplicar às massas. As figuras do crime mental e da polícia do pensamento, descritas por Orwell, constituem metáforas fortes para a despersonalização do individuo, que por via da imposição forçada da ordem e do celibato procuram redesenhá-lo enquanto ser, afastando-o dos traços que definem a sua humanidade. A história, a memória, a língua, a cultura, a afetividade - tudo é branqueado de forma a ser substituído por uma nova narrativa, materializada pela máquina de propaganda - uma hiperrealidade ${ }^{19}$ criteriosamente orquestrada.

\section{Terrorismo visual}

O género reality $T V$ é representativo desta realidade fabricada pelos média, que Jean Baudrillard caracteriza como "uma banalidade sintética manufaturada em circuito fechado" (Baudrillard, 2001: 181) 20 $^{20}$ "um mero detalhe holográfico da realidade global" (Baudrillard, 2001: 182) ${ }^{21}$, tornando o fenómeno televisivo num evento mediático em si mesmo, autorreferenciado no seu próprio universo de significação, e que chega a tomar conta das grelhas de programação noticiosa dos canais sensacionalistas. Isto porque, é na televisão ou nos feeds de Internet que hoje se parece procurar a verdade, ou seja,

\footnotetext{
${ }^{19}$ Apropriamo-nos aqui do termo do filósofo francês Jean Baudrillard. Segundo Baudrillard (1991), os média operam uma reinterpretação aquém mundo que nos salvaguarda das suas tensões e nos aproxima de uma ideia de felicidade. Esta vertigem de realidade ou "hiper-real", que supera o próprio real e se serve dele apenas como álibi, define a esfera do "simulacro" na qual os média autonomizam o real através de signos multiplicados da realidade, manipulando o quotidiano fabricado enquanto lugar do consumo. Neste sentido, o autor reporta a uma crise da representação e do sentido, na medida em que deixamos de distinguir o que é verdadeiro e o que é falso, sendo que o "simulacro" constitui uma simulação que esconde constantemente que o é, assente num enorme poder de dissimulação.

${ }^{20}$ Tradução da autora.

${ }^{21}$ Tradução da autora.
} 
o real que nos é dado já processado e com a melhor aparência possível. É nesta mesma arena que se joga a dimensão transpolítica dos acontecimentos, ou melhor, dos "nãoeventos" ${ }_{2}$ que são alimentados pela hegemonia informacional mediática.

Esta noção de "não-evento" ou "média-evento", que encontra as suas origens na proposta de "pseudo-evento" introduzida por Daniel Boorstin nos anos 60, é explorada por Jean Baudrillard enquanto fenómeno que decorre da cultura de massas globalizada e preconiza a dimensão de entretenimento e espetáculo em tudo o que é passível de ser noticiado, o que equivale a dizer, ser traduzido num discurso seletivo e filtrado em prol de uma mensagem inscrita num guião de uma realidade que é hoje ficção (Merrin, 2005: 63-80). O olhar crítico de Baudrillard, tornado público antes, durante e após o conflito armado que decorreu no Iraque entre agosto de 1990 e fevereiro de 1991, denuncia o maior média-evento que se conheceu até à data, também designado como Video Game War, Cyber War, ou de forma ampla como Guerra Tecnológica. Pela primeira vez, a sofisticação de armamento inteligente monitorizado por tecnologias de visualização e o acesso a filmagens na frente de combate (emitidas em tempo real e de forma global pela $C N N$ ) determinam, segundo o autor, a sublimação da representação sobre os acontecimentos e elegem a televisão como quarto poder, palco da opinião pública que opera uma imposição unilateral simbólica sobre a audiência.

Quando o controverso teórico francês afirma, com o seu ceticismo pós-moderno, que "a Guerra do Golfo nunca existiu" (Baudrillard, 1995) ${ }^{22}$, cria uma fratura no discurso hegemónico ocidental, pondo em causa a idoneidade dos média e chocando não só a audiência bem como os seus pares. Tal negação radical é amplamente contestada em 1997 por Arlindo Machado, que sublinha o quão real a guerra foi para todas as suas vítimas, apesar da emissão do que se revelou ser um fastidioso anti-espetáculo de "esvaziamento do olhar" e "ruído mirrado e distante" que resultou da profunda censura militar que bloqueou toda a iconografia que contrariasse um cenário vitorioso (Machado, 2007: 263). Na perspetiva de Machado, tal manipulação e fabricação nada têm a ver com a essência do formato noticioso televisivo, pautado por uma discursividade polifónica aberta à discussão, oposta à domesticação ideológica do telespectador, como veiculado pelo crítico francês.

Não obstante, mais do que oferecer-se a uma interpretação literal, a conhecida afirmação de Jean Baudrillard sobre a inexistência da guerra sublinha, a nosso ver, não

\footnotetext{
${ }^{22}$ No livro The Gulf War Did Not Take Place (1995), estão compilados e desenvolvidos os três ensaios que Jean Baudrillard publicou entre Janeiro e Março de 1991 nos jornais Libération e The Guardian, nos quais semeia o ceticismo e a descrença, à medida que explora a ideia de negação da guerra: os ensaios foram respetivamente "La guerre du Golfe n'aura pas lieu", publicado a 4 de Janeiro; "La guerre du Golfe a-t-elle vraiment lieu?", publicado a 6 de Fevereiro e, finalmente, "La Guerre du Golfe n'a pas eu lieu”, publicado a 29 de Março.
} 
a sua ausência, mas antes o seu excesso, preconizado pela repetição de imagens que exterminam simbolicamente o inimigo - enquanto signo do mal -, antes mesmo de o confrontar. Baudrillard contesta essencialmente a naturalização que pauta a nossa aceitação da guerra sem questionar o sentido de irrealidade que subjaz à sua disseminação, alimentada mais pela especulação e pelo comentário mediático sectário do que pela imparcialidade dos factos. Para Baudrillard, gera-se consequentemente uma total apatia e distanciamento do espectador, que parece consumir indiferentemente um reality-show ou um cenário bélico com cadáveres enquadrados como naturezasmortas.

Embora com uma postura crítica evidentemente distinta em termos axiomáticos da de Baudrillard, Susan Sontag refere-se igualmente à indiferença provocada pelas imagens televisivas de violência. Refletindo sobre a passagem das imagens de sofrimento e horror, do domínio histórico do fotojornalismo ao domínio televisivo, Sontag descreve o modo particular como estas representações integram atualmente as "[...] imagens e sons de sala de estar" (Sontag, 2003: 25):

A questão anda à volta da visão que temos do principal meio noticioso, a televisão. Uma imagem é esvaziada da sua força dependendo do modo como é usada, de onde e de quantas vezes é vista. As imagens mostradas na televisão são por definição imagens que, mais tarde ou mais cedo, cansam. $O$ que parece ser insensibilidade tem a sua origem na instabilidade da atenção que a televisão está organizada para despertar e saciar através do seu excesso de imagens. A fartura de imagens mantém a atenção leve, móvel, relativamente indiferente ao conteúdo. O fluxo de imagens exclui uma imagem privilegiada. O que conta em televisão é que se pode mudar de canal, que é normal mudar de canal, ficar-se insatisfeito, aborrecido. Os consumidores desanimam. Têm de ser estimulados, de ser empurrados, continuamente. O conteúdo não é mais do que um destes estimulantes. Uma atenção mais reflexiva ao conteúdo exigiria uma certa intensidade da consciência - precisamente aquela que é atenuada pelas expectativas atribuídas às imagens disseminadas pelos media, cujo despojamento de conteúdo contribui decisivamente para o amortecimento das emoções (Sontag, 2003: 110-111).

O imediatismo e superficialidade da mediatização dos eventos operam, de certo modo, uma suavização que atenua os danos e a real interpretação dos mesmos, fazendo com que a imagem se sobreponha ao conteúdo que se torna descartável. A este nível, o que resta é o fluxo e repetição permanentes de uma visibilidade que, segundo Jean Baudrillard, se tornaria pornográfica, na medida em que as imagens se sobreporiam à violência dos acontecimentos, virtualizando-os (Baudrillard, 1996). Em War Porn (2004), Baudrillard enumera, além da Guerra do Golfo, outros média-eventos que cristalizam, em imagens emblemáticas, ataques cáusticos à supremacia americana: a destruição das torres gémeas nos ataques de 11 de Setembro de 2001 e o escândalo das imagens de tortura da prisão de Abu Ghraib que vieram a público em 2004. 
O caso de Abu Ghraib ilustra o poder da denúncia por imagens que colocou no centro da discussão a própria definição de tortura, veiculada por registos visuais capturados de forma amadora pelos soldados americanos, que posam e sorriem para a câmara exibindo os seus troféus. A presença de uma câmara neste contexto, além de demarcar contornos particularmente perversos, exerce uma influência transformadora sobre o evento, pois altera de forma premeditada o comportamento dos agentes e as ações alvo de registo, fazendo coincidir a ação e o meio num só plano, o plano da encenação - da imagem. Justificadas enquanto forma de divertimento e descompressão do contexto de tensão militar em que os intervenientes se encontravam, as imagens de humilhação sádica altamente sexualizadas e religiosamente ofensivas ao islamismo, expressam uma violação clara dos direitos humanos. Segundo Nicholas Mirzoeff, um verdadeiro regime imperial subjaz à visualidade globalizada em que vivemos, na qual todos os sujeitos são simultaneamente vigilantes e vigiados, sendo o corpo a manifestação máxima dessa visualidade (Mirzoeff, 2006: 22). Neste sentido, as imagens de Abu Ghraib demonstram como o poder sobre o corpo de alguém significa o controlo da sua subjetividade suscitando, paralelamente, a celebração fetichista do corpo nu, cuja sodomização recupera uma dimensão colonial do Outro - visto como oriental, nãohumano e desviante (Mirzoeff, 2006).

No entanto, estas imagens parecem pairar impunes como mera iconografia que circula livremente pelo espetáculo mediático, sendo frequentemente alvo de apropriação, ora em tom paródico ora em tom de pastiche ${ }^{23}$. No fundo, acabam por representar apenas uma fuga de informação no espaço visual que escapou à administração de Bush, pois, na verdade, após a descontextualização operada pela disseminação online, pouco dizem sobre o seu conteúdo para além de um ímpeto voyeurista e exibicionista. A sua dimensão icónica chega mesmo a ser celebrada através da exibição em contexto artístico em 2004, no International Center of Photography em Nova lorque, sob o título Inconvenient Evidence, que segundo o curador Brian Wallis nos oferece uma nova perspetiva sobre o que é a guerra e o mundo mediático no século XXI.

\section{Considerações finais}

O presente artigo explora o conceito de televisualidade como paradigma visual vigente, associado aos meios de telecomunicação e a uma visualidade remota que reporta ao

\footnotetext{
${ }^{23}$ A definição corrente de pastiche nos dicionários especializados no domínio da arte e da literatura, mas também em dicionários gerais como o EnlishDictionaryOnline, faz corresponder este termo francês derivado do termo italiano pasticcio, a ideia de pasta/ e amálgama de elementos. É utilizado, em particular no campo da literatura e das artes, para designar uma estratégia intertextual que recorre deliberadamente à apropriação e mistura estilística de referências de outros autores como forma de tributo, em oposição à intertextualidade paródica, usada de forma depreciativa pela sua abordagem satírica.
} 
fluxo de imagens disseminadas através de ecrãs. Deste modo, é abordada a dualidade da imagem televisiva, nomeadamente a sua riqueza sinestésica e plástica, tal como evidenciado por Marshall McLuhan e John Thornton Caldwell, em oposição às críticas ao poder ideológico e alienador associado ao dispositivo televisivo, enquanto veículo de conteúdos pré-digeridos e medíocres direcionados para as massas. Ainda na viragem para a década de 70 , refere-se como o meio televisivo foi igualmente problematizado por artistas como Nam June Paik, que destacou o potencial criativo e comunicativo do feedback, da participação do espectador, bem como da emissão global em tempo real. Não obstante, a globalização efetiva e banalização da imagem em tempo-real consolidam-se já na década de 90, com o funcionamento pleno da World Wide Web, que catapulta a conectividade permanente e a diluição das fronteiras entre a realidade dentro e fora do ecrã, nomeadamente na afirmação dos géneros reality, que evoluem para uma exploração multiplataforma. A este nível, destaca-se o legado da obra Mil Novecentos e Oitenta e Quatro de George Orwell, designadamente na problematização da vigilância e a construção icónica da figura do Big Brother, cuja repercussão se faz sentir até hoje, e perpassa além dos domínios mediático e artístico.

É neste contexto que se apresentam ainda as experiências-limite desenvolvidas por Josh Harris, que, na viragem para o novo milénio, desvela um caminho inusitado, embora visionário, na utilização da tecnologia enquanto paradigma de socialização, que explicita o poder que a mediatização confere à imagem videogravada, nomeadamente para a construção de celebridades instantâneas, cujo valor incrementa à velocidade do fluxo da sua circulação mediática. Este contexto continua a remeter, sem dúvida, para a realidade atual, que apenas ganha existência quando projetada através dos ecrãs que medeiam o nosso dia-a-dia. Tal dimensão, ecoa igualmente nos conceitos de "hiperrrealidade" - cujos signos são esvaziados de referente - e de "não-evento" ou de "média-evento" - alusivo à fabricação dos média - abordados por Jean Baudrillard, que radicaliza um ceticismo claro face aos média em geral, com enfoques específicos no que respeita aos géneros televisivos reality e à cobertura mediática de eventos como a Guerra do Golfo ou à disseminação de imagens violentas como as dos ataques do 11 de setembro e as imagens de tortura registadas em Abu Ghraib. A multiplicação deste tipo de imagens, a par de tantas outras replicadas por todos os canais noticiosos, desenham uma prática emergente que poderíamos designar por terrorismo visual.

Numa conjuntura onde tudo é passível de ser registado, tornamo-nos alvos recorrentes dos dispositivos visuais e recoletores compulsivos de imagens, numa lógica algo 
predatória ${ }^{24}$. Na televisualidade construída pela naturalização da cultura mediática, o que se torna o alvo principal de julgamento e contemplação já não são os atos mas as imagens, que, no nosso direito de olhar ${ }^{25}$, constituem uma "moralidade útil" (Sontag, 2003: 59). Na perspectiva de Susan Sontag, as imagens que pairam nas nossas salas de estar seriam apenas um sintoma da "anestesia moral e emocional" (2003: 107) que nos impede de agir e de sentir e que nos persegue quer quando contemplamos o sofrimento de longe, através dos nossos ecrãs, quer quando o contemplamos de perto, sem a mediação destes ${ }^{26}$. Uma vez na Internet, por mais que se tente limpar o rasto destas imagens, elas continuam acessíveis, de forma livre e indiferenciada - como uma espécie de maldição do retorno das imagens que, uma vez em circulação no contexto digital em que vivemos, escapam a qualquer censura ou controlo:

No nosso salão digital de espelhos, as imagens não vão desaparecer. Sim, parece que uma imagem vale mais do que mil palavras. E mesmo que os nossos líderes optem por não olhar para elas, surgirão milhares de novas fotografias instantâneas e vídeos. Imparáveis (Sontag, 2004). ${ }^{27}$

Se estas imagens podem ditar em certa medida a nossa indiferença e apatia, são também elas que podem desencadear processos de reflexão crítica e de acção histórica. Com efeito, são elas que determinam a forma como se olham, julgam e recordam os conflitos, as tensões e as violências, sendo que, em geral, estas visões persistentes constroem a nossa cultura visual coletiva, onde uma imagem remete sempre para outra imagem (Sontag, 2003: 91-92). A cultura visual, por via quer da arte quer dos média, pode desempenhar um papel fulcral na medida em que permite lançar,

\footnotetext{
${ }^{24}$ Sobre a perspetiva de Susan Sontag relativamente a esta lógica predatória veja-se: "A fotografia necessitou de novos territórios de discriminação, dividindo o espetáculo visível do mundo em objetos agora considerados dignos e indignos de serem fotografados. Ao produzir novos e recém-respeitáveis tipos de espectadores e voyeurs que são definidos por uma participação mais viciada nos eventos que documentam, o ato de fotografar simultaneamente certifica e limita a experiência. Para Sontag, as relações mais intratáveis entre sujeito/objeto ritualizadas pela fotografia têm um potencial predatório: como a arma que superficialmente se assemelha, a câmara penetra, viola" (Jacobs, 2001: 20).

${ }^{25}$ Conforme enunciado por Jacques Derrida no acompanhamento textual que fez às obras fotográficas de Marie-Françoise Plissart (1985), o "direito de olhar", na sua incursão quer no espaço público quer privado, aponta para as políticas do olhar nas suas dimensões de poder e vigilância, bem como para os limites da representação e as fronteiras entre o visível e o invisível, em particular no que respeita ao cariz referencial da fotografia. Martin Jay ressalta o modo como Derrida abordada no referido ensaio a discursividade das imagens, enfatizando a negociação da matriz simbólica encapsulada pelo seu produtor e a matriz do imaginário ativada pelo leitor, resultando em diversas apropriações e expropriações do ponto de vista que a imagem fornece (Jay, 1993:518-521). Tal facto, na ótica de Derrida, precipita uma escalada de violência decorrente da autoridade (a par da falta de controlo e regulação) conferida quer a quem opera a câmara, quer aos meta-discursos gerados em torno dessas imagens, envolvendo questões jurídico-políticas da produção e consumo das imagens, re-equacionadas nos moldes do "telepoder" e "teleconhecimento" introduzidos pelas "teletecnologias" (Derrida \& Stiegler, 2002:31-40).

26 "Têm-se acusado as imagens de serem uma maneira de ver o sofrimento à distância, como se houvesse outra maneira de ver. Mas ver de perto - sem a mediação de uma imagem - é ainda ver apenas" (Sontag, 2003: 122).

${ }^{27}$ Tradução da autora.
} 
não só ao nosso olhar, mas também à nossa capacidade de reflexão, de tomada de consciência e de ação, um repto que se opõe à simples relação superficial que homogeneiza todo o plano visual parametrizado por hashtags. Alguns dos gestos artísticos e as intervenções mediáticas que mencionámos ao longo deste artigo são exemplares de uma resposta condigna a este repto, que se propagaria num contexto de profusa intertextualidade, de plena cultura da reciclagem e arquivismo, segundo a análise de William Merrin (2005: 70). Se esta cultura do arquivo e do diálogo entre imagens se fez notar com particular evidência nos ditos novos média, ela é também, a nosso ver, manifesta nas apropriações da televisão. Para pensadores como Marshall McLuhan, John Thornton Caldwell e Arlindo Machado e para artistas como Nam June Paik, a televisão ainda não esgotou o seu potencial estético e participativo, enquanto sistema técnico-expressivo, nomeadamente no que respeita ao desenvolvimento da sua linguagem através de estratégias narrativas transmediáticas.

\section{Bibliografia}

Baudrillard, J. (1991). Simulacros e Simulação. Lisboa: Relógio d’Água.

Baudrillard, J. (1995). The Gulf War Did Not Take Place. Bloomington \& Indianapolis: Indiana University Press.

Baudrillard, J. (1996). TV Fantasies, in Baudrillard, J. (2002). Screened Out (pp.186190). Londres, Nova lorque: Verso.

Baudrillard, J. (2001). Dust Breeding, in Baudrillard, J. (2005). The Conspiracy of Art Manifestos, Interviews, Essays (pp. 181-187). Nova lorque, Los Angeles: Semiotext(e). Baudrillard, J. (2004). War Porn, in Baudrillard, J. (2005). The Conspiracy of ArtManifestos, Interviews, Essays (pp. 205-209). Nova lorque, Los Angeles: Semiotext(e). Caldwell, J. T. (1995). Televisuality: style, crisis and authority in American television. New Brunswick e New Jersey: Rutgers University Press.

Castello Branco, P. (2011). Imagem, Corpo, Tecnologia: A Função Háptica das Novas Imagens Tecnológicas. Lisboa: Fundação Calouste Gulbenkian.

Dancyger, K. (2011). The Technique of Film and Video Editing. History, Theory, and Practice. Massachusetts: Focal Press / Elsevier.

Debord, G. (1991). A Sociedade do Espectáculo. Lisboa: Mobilis in Mobile.

Derrida, J.; Stiegler, B. (2002). Echographies of Television. Filmed Interviews.

Cambridge, Oxford, Malden: Polity Press.

Fincher, D. (1995). Se7en. EUA: Cecchi Gori Pictures, Juno Pix, New Line Cinema. [Filme de $127 \mathrm{~min}]$.

Flusser, V. (1985). Filosofia da Caixa Preta. Ensaios para uma futura filosofia da fotografia. São Paulo: Editora Hucitec. 
Friedberg, A. \& Guins, G. (2004). Televisual Space (Editorial). Journal of Visual Culture 2004. Vol 3. N²,131-132.

Grilo, J. M. (2006). O Cinema da não-ilusão - Histórias para o Cinema Português. Lisboa: Livros Horizonte.

Hanhardt, J. (2000). The Worlds of Nam June Paik. Consultado em http://www.paikstudios.com/.

Jacobs, K. (2001). The Eye's Mind: Literary Modernism and Visual Culture. Ítaca, Londres: Cornell University Press.

Jameson, F. (2003). Postmodernism, or, the Cultural Logic of Late Capitalism. PostContemporary Interventions. Durham: Duke University Press.

Jay, M. (1993). Downcast Eyes. The Denigration of Vision in Twentieth-Century French Thought. Berkeley, Los Angeles, Londres: University of California Press. Jenkins, H. (2008). Convergence Culture. Where Old and New Media Collide. Nova lorque, Londres: New York University Press.

Lacan, J. (1964). What is a Picture, in Miller, J.A. (Ed.) (1981) The Four Fundamental Concepts of Psycho-Analysis (pp.105-119). Nova lorque, Londres: W.W. Norton \& Company.

Lipovetsky, G., Serroy, J. (2010). O Ecrã Global. Cultura Mediática e Cinema na Era Hipermoderna. Lisboa: Edições 70.

Machado, A. (2000). A Televisão levada a sério. São Paulo: Editora Senac.

Machado, A. (2007). Pré-cinemas \& Pós-cinemas. São Paulo: Papirus Editora.

McLuhan, M. (1977). A Galáxia de Gutenberg: a formação do homem tipográfico. São Paulo: Companhia Editora Nacional.

McLuhan, M. (2003). Understanding Media. London, New York: Routledge Classics. Merrin, W. (2005). The delirious spectacle of the non-event. In Baudrillard and the Media: A Critical Introduction (pp. 63-80). Cambridge, Malden: Polity Press.

Mirzoeff, N. (2006). Invisible Empire: Visual Culture, Embodied Spectacle, and Abu Ghraib. Radical History Review 95, Spring 2006, 21-44. Consultado em http://www.nicholasmirzoeff.com/Images/Mirzoeff_InvisibleEmpire.pdf. Mitchell, W.J.T. (2005). What do Pictures Want? The Lives and Loves of Images. Chicago, Londres: The University of Chicago Press.

Mondzain, M.J. (2009). A imagem pode matar? Lisboa: Nova Vega. Mueller, R. (1994). Valie Export: Fragments of the Imagination. Women Artists in Film. Indianapolis: Indiana University Press.

Orwell, G. (2007) Mil Novecentos e Oitenta e Quatro. Lisboa: Antígona.

Plissart, M. F. (1985) Droit de regards. Avec une lecture de Jacques Derrida. Paris:

Éditions de Minuit. 
Radford, M. (1984). Nineteen Eighty-Four (1984). Reino Unido: Umbrella-Rosenblum Films Production, Virgin. [Filme baseado no romance de George Orwell, $113 \mathrm{~min}$ ].

Rodrigues, A. (1989). Do dispositivo televisivo. Revista de Comunicação e Linguagens. $N^{\circ} 9,61-65$.

Sontag, S. (2003). Olhando o Sofrimento dos Outros. Lisboa: Gótica.

Sontag, S. (2004). Regarding the Torture of Others. New York Times Magazine. May 23, 2004. Consultado em: http://www.nytimes.com/2004/05/23/magazine/regardingthe-torture-of-others.html.

Timoner, O. (2009). We Live in Public. Estados Unidos da América: Interloper Films, Pawn Shop Creatives. [Documentário de $91 \mathrm{~min}$ ].

Weir, P. (1998). The Truman Show. Estados Unidos da América: Paramount Pictures, Scott Rudin Productions. [filme de $103 \mathrm{~min}$ ].

Ana Velhinho é designer de comunicação, investigadora do Centro de Investigação e de Estudos em Belas-Artes (CIEBA) da Faculdade de Belas Artes da Universidade de Lisboa e colabora no projeto de investigação PSF - International Festival of Art, New Media and Cybercultures. Encontra-se a desenvolver a sua tese de doutoramento na Faculdade de Belas-Artes da Universidade de Lisboa, na área de teoria da imagem, com particular enfoque em metodologias visuais e na influência da cultura pós-internet nas práticas e literacias visuais.

\ana.velhinho@gmail.com 